\title{
Research on Threshold Effect of Housing Price on Real Estate Inventory
}

\author{
Dong Zhang \\ School of Finance \\ Zhongnan University of Economics and Law \\ Wuhan, China 430073
}

\author{
Haojie Wang \\ School of Finance \\ Zhongnan University of Economics and Law \\ Wuhan, China 430073
}

\begin{abstract}
Through the systematic GMM estimation of the panel data of 35 large and medium-sized cities in China from 2005 to 2016, this paper verifies the nonlinear relationship between housing prices and real estate inventory. On this basis, the threshold regression model is established by modifying the econometric model. It is suggested that cities with high real estate inventory should guide the housing price to return to a reasonable range, while cities with low inventory should increase land supply to strengthen housing security.
\end{abstract}

Keywords-housing price; real estate inventory; system GMM estimation; threshold regression

\section{INTRODUCTION}

In the first half of 2019, the news of housing sale in Hegang was widely reported by the media, with the houses being sold at the price of "cabbage", indicating that the city's real estate inventory is under great pressure. As a matter of fact, by December 2018, inventory in 44 of the 100 key cities in China had increased year on year, while in 10 cities, including JingDeZhen, HuiZhou and LangFang, inventory had increased by more than $50 \%$ year on year. History always amazing similar, from the point of relevant statistics, China's commercial housing sale area reached 719 million square meters at the end of 2015, and the area of commercial housing for sale in China is still as high as 695 million square meters at the end of 2016, the decline was only $3.2 \%$, thus it can be seen, even if the implementation of the preferential policy that buy a house, high inventory phenomenon still exists, commercial housing inventory to effect is not obvious. Although the housing price and inventory in some cities have returned rationally to a certain extent nationwide, due to the cyclical development of the real estate market itself, inventory in some cities has been gradually high since 2018 . Therefore, after the exit of the real estate destocking policy at the national level, it is of certain theoretical and guiding significance to study the relationship between housing price and real estate inventory to observe the cyclical fluctuation of real estate inventory and implement precise real estate regulation.

\section{LITERATURE REVIEW}

At present, researches on China's real estate inventory are mostly concentrated in China. Due to the limitation of geographical factors, there are few researches on China's real estate inventory abroad. However, foreign studies on real estate inventory mainly focus on the calculation of vacancy rate and how to maintain the vacancy rate within a reasonable range. The United States is the first country in the world to publish the vacancy rate calculation index, while the European Union, Japan and other countries also have different calculation on the vacancy rate (Wen Jianwu et al, 2010). At present, there is no uniform calculation standard and caliber to measure the vacancy rate. Struky et al. (1983) believed that the reasonable vacancy rate range between developed countries and developing countries is different. When the housing vacancy rate is too high, housing price should be adopted to adjust the excess housing.

Domestic theoretical research on real estate inventory mainly focuses on motivation and countermeasure analysis. In terms of the motivation of real estate inventory, $\mathrm{Li}$ Xiaoman (2017) mainly discussed the reasons for the coexistence of high inventory and high housing price in some hot second-tier cities. Fang Yao (2016) sorted out the influencing factors of real estate inventory through empirical analysis, including housing price, income and economic growth. Real estate countermeasures to inventory, Wang Xiaoguang (2017) think the destocking of 2016 is unsatisfactory not only failed to reduce inventory but also leverage the real estate market bubble increased, the secondtier cities should focus on inventory to curb speculative demand, while three or four line cities reduce inventory should be combined with a new type of urbanization. Hu Zuquan (2016) believes that speeding up the citizenization of migrant workers is the key to fighting a "destocking" war of annihilation, and in addition, housing price should be reduced and land supply should be improved. Zhou Youman (2016) believes that real estate destocking can be accelerated from the two aspects of real estate enterprise transformation and financial institutions boosting.

The empirical research on real estate inventory in China mainly focuses on the impact of real estate inventory on national economy and the impact of external factors on real estate inventory. In terms of the impact of real estate inventory on the national economy, Liu Xing and Zhang Jing (2017) investigated the impact of the money supply and commodity housing inventory on the housing price, and studied the relationship between the money supply and commodity housing inventory in China and the housing price 
supply and demand of housing, and the following formula is established:

$$
F=S-D
$$

Since housing price will affect both supply and demand of housing, so both $S$ and $D$ are functions of $p$, the above equation can be rewritten as:

$$
F(p)=S(p)-D(p)
$$

In order to study the impact of housing price on real estate inventory, the partial derivative of $p$ is obtained as follows:

$$
\frac{d F(p)}{d p}=\frac{d S(p)}{d p}-\frac{d D(p)}{d p}
$$

When the housing price rises, $\frac{d S(p)}{d p}$ is positive, while $\frac{d D(p)}{d p}$ is negative, $\frac{d F(p)}{d p}$ must be positive, so real estate inventory should increase with the rise of housing price, and they are positively correlated. The rise of housing price stimulates the supply of housing by real estate developers, while the high housing price restrains the demand of residents of houses. Therefore, theoretically, housing prices should have a positive impact on real estate inventory.

\section{B. Analysis of the Non-linear Relationship Between Residents' Disposable Income and Inventory Through Housing Price}

Domestic and foreign scholars have shown that housing price and residents' disposable income are the most important factors influencing housing demand. Theoretically, the increase of residents' disposable income will stimulate residents' demand for house purchase. That is to say, under the assumption that housing price and other commodity prices remain unchanged, housing consumption will increase with the increase of income, $\triangle D_{1}$ is positive. When the housing price changes, there will be both substitution effect and income effect. The rise of housing price will inhibit the purchase demand of residents and produce a negative substitution effect (denoted by $\triangle D^{S}$ ). Moreover, since housing is a normal commodity, the rise of housing price will cause the real income of residents to decrease, thus the consumption of housing will decrease, that is, negative income effect will be generated simultaneously (denoted by $\left.\triangle D^{N}\right)$ :

$$
\triangle D_{2}=\triangle D^{S}+\triangle D^{N}
$$

When residents' disposable income and housing prices rise at the same time, whether the total demand for housing will increase depends on the size of $\triangle D_{1}$ and $\triangle D_{2}$. The speed of inventory increase is affected by both income and housing price. Although both income and housing price have 
Research hypothesis 1: The increase of real estate inventory depends on the rise of housing price, and housing price will have a non-linear effect on real estate inventory.

Research hypothesis 2: With the increase of residents' disposable income, the positive impact of housing price on real estate inventory is increasing.

\section{EMPIRICAL ANALYSIS}

With the increase of residents' disposable income, the of positive impact of housing price on real estate inventory will change, and there may be a non-linear relationship between housing price and inventory. At the same time, existing studies also show that the housing price rose rapidly from 2005 to 2010, but the growth rate of household income was relatively slow, which limited social purchasing power. Therefore, with the increase of urban residents' disposable income, the positive impact of housing price on real estate inventory may be strengthened.

Based on the above theoretical analysis, this paper proposes the following hypothesis:

TABLE I. DESCRIPTIVE STATISTIC

\begin{tabular}{|l|l|l|l|l|l|l|}
\hline \multicolumn{1}{|c|}{ Variables } & \multicolumn{1}{c|}{ Meaning } & Sample Size & Mean Value & Standard Deviation & \multicolumn{1}{c|}{ Minimum } & \multicolumn{1}{c|}{ Maximum } \\
\hline fsa & Real estate inventory & 420 & 3142251 & 3715145 & 133600 & 206459 \\
\hline p & House prices & 420 & 5904.02 & 3840.97 & 1552 \\
\hline pcdi & Per capita disposable income & 420 & 23846.31 & 17874.05 & 24723 \\
\hline ls & Land supply & 420 & 8790792 & 7616949 & 7990 & 609496 \\
\hline lr & The interest rate & 420 & 6.02 & 0.68 & 39906286 \\
\hline $\mathrm{dp}$ & The population density & 420 & 644.19 & 402.71 & 4.75 & 7.56 \\
\hline
\end{tabular}

In order to avoid false regression, it is necessary to perform unit root test on the data involved in the housing demand measurement model before regression analysis of the model. Since the data used in this paper are panel data, it is necessary to perform panel unit root test on the data. Generally, the panel unit root is tested in the following four ways: LLC test, IPS test, Fisher-Dfuller (ADF) test and Fisher Phillips-Perron (PP) test. LLC test was homogeneous panel unit root test, while IPS test, Fisher-Dfuller (ADF) test and Fisher Phillips-Perron (PP) test were heterogeneous panel unit root test. In order to avoid heteroscedasticity problems in subsequent regression analysis, all variables were converted to natural logarithm form before the unit root test. The test results show that the sequence of horizontal values of all variables is stable and meets the requirements of modeling. The panel unit root test results of $\ln p$ and $\operatorname{lnfs} a$ are shown in "Table II":

TABLE II. UNIT RoOT TEST RESULTS

\begin{tabular}{|l|l|l|l|l|}
\hline \multicolumn{1}{|c|}{ Variables } & \multicolumn{1}{|c|}{ Levin-Lin } & \multicolumn{1}{c|}{ IPS } & \multicolumn{1}{|c|}{ Fisher-ADF } & \multicolumn{1}{|c|}{ Fisher-PP } \\
\hline \multirow{2}{*}{$\operatorname{lnfsa}$} & $-18.6494 * * *$ & $-7.1205 * * *$ & $7.4077 * * *$ & $5.6573 * * *$ \\
& $(0.0000)$ & $(0.0000)$ & $(0.0000)$ & $(0.0000)$ \\
\hline \multirow{2}{*}{$\operatorname{lnp}$} & $-14.0097 * * *$ & $-2.9221 * * *$ & $25.1891 * * *$ & $4.3090 * * *$ \\
& $(0.0000)$ & $(0.0017)$ & $(0.0000)$ & $(0.0000)$ \\
\hline
\end{tabular}

a. Note: $\mathrm{P}$ values are shown in brackets. “"**,, “" “*”, and “"” mean significant at $1 \%, 5 \%$ and $10 \%$ levels, respectively.

1) Testing the non-linear relation between housing price and inventory

Theoretically, indexes that can affect the sales area of commercial housing and the area for sale will have a certain

$$
\operatorname{lnfs} a_{i t}=\beta_{0}+\beta_{1} \ln f s a_{i t-1}+\beta_{2} \operatorname{lnp}_{i t}+\beta_{3} C_{i t}+\gamma_{t}+u_{i}+\xi_{i t}
$$

Where, ${ }^{\ln f s a_{i t}}$ and $\operatorname{lnfs} a_{i t-1}$ respectively represent the area $i$ for sale of the city's commercial housing in the period of $t$ and the period of $t-1,{ }^{\ln p_{i t}}$ is the housing price of city $i$ in the period $t ; C_{i t}$ is the combination of control variables; ${ }^{\gamma}$ is impact on the real estate inventory, and the current real estate inventory will also be affected by the previous inventory. Therefore, the specific form of the dynamic panel model established in this paper is as follows: the time fixed effect; ${ }^{u_{i}}$ is the individual fixed effect; $\xi_{i t}$ is the random error term.

In order to verify whether there is a linear relationship between housing price and inventory generation, this paper 
adds the square term on the basis of equation (5) and

establishes the following model:

$$
\operatorname{lnfs} a_{i t}=\beta_{0}+\beta_{1} \ln s s a_{i t-1}+\beta_{2} \ln p_{i t}+\beta_{3} \ln p_{i t}^{2}+\beta_{4} C_{i t}+\gamma_{t}+u_{i}+\xi_{i t}
$$

At the same time, in order to investigate the adjustment effect of household income on housing price and inventory, we introduced the interaction item between housing price level and per capita disposable income of urban

$$
\ln f s a_{i t}=\beta_{0}+\beta_{1} \ln f s a_{i t-1}+\beta_{2} \ln p_{i t}+\beta_{3} \ln p_{i t} * \operatorname{lnp} c d i_{i t}+\beta_{4} C_{i t}+\gamma_{t}+u_{i}+\xi_{i t}
$$

In this paper, equations (1) - (3) are respectively estimated by the generalized moment estimation method. System of generalized moment estimation is improved on the base of generalized moment estimation method can effectively solve the dynamic change of explanatory variables and the endogenous problem of explanatory variables in the model (Richard and Stephen,1998), it can also control area fixed effect and annual fixed effect. In view of the revised two-step system GMM is more robust than step system, this paper uses a two-step system GMM estimation. In order to eliminate the impact of inflation on commodity housing price, urban residents' per capita disposable income and interest rate, we use consumer price index to convert commodity housing price. Urban residents' per capita disposable income and interest rate into fixed base price index (based on 2005) to get the actual amount. In addition, considering the possible multicollinearity of the square term and the interaction term in equations (5) and (6), in order to ensure the significance of the original variable coefficients, the constructed square term and the interaction term were decentralized in this study to ensure the reliable estimation results.

The estimated results of the above three formulas are shown in "Table III":

\begin{tabular}{|c|c|c|c|}
\hline Variables & Model(1) & Model(2) & Model(3) \\
\hline $\operatorname{lnfsa} a_{i t-1}$ & $\begin{array}{l}0.734^{* * *} \\
(0.016)\end{array}$ & $\begin{array}{l}0.677^{* * *} \\
(0.022)\end{array}$ & $\begin{array}{l}0.643^{* * *} \\
(0.020)\end{array}$ \\
\hline $\operatorname{lnp}_{\text {it }}$ & $\begin{array}{l}0.231^{\text {*** }} \\
(0.020)\end{array}$ & $\begin{array}{l}0.260^{* * *} \\
(0.025)\end{array}$ & $\begin{array}{l}0.277^{\text {*** }} \\
(0.031)\end{array}$ \\
\hline $\ln p_{i t}^{2}$ & & $\begin{array}{l}0.127^{* * * *} \\
(0.017)\end{array}$ & \\
\hline $\operatorname{lnp}_{i t}{ }^{*} \operatorname{lnpcdi}_{i t}$ & & & $\begin{array}{l}0.272^{* * *} \\
(0.037)\end{array}$ \\
\hline $\operatorname{lnl} s_{\mathrm{it}}$ & $\begin{array}{l}0.36^{* *} \\
(0.018)\end{array}$ & $\begin{array}{l}0.380^{* * *} \\
(0.027)\end{array}$ & $\begin{array}{l}0.393^{\text {*** }} \\
(0.027)\end{array}$ \\
\hline $\ln l r_{\text {it }}$ & $\begin{array}{l}-0.128^{*} \\
(0.067)\end{array}$ & $\begin{array}{l}-0.209^{* * *} \\
(0.072)\end{array}$ & $\begin{array}{l}-0.206^{* * * *} \\
(0.068)\end{array}$ \\
\hline $\operatorname{lndp}_{\text {it }}$ & $\begin{array}{l}-0.04 \\
(0.048)\end{array}$ & $\begin{array}{l}-0.096^{* * *} \\
(0.040)\end{array}$ & $\begin{array}{l}-0.067^{*} \\
(0.041)\end{array}$ \\
\hline Sargan Test & $\begin{array}{l}32.75 \\
(0.71)\end{array}$ & $\begin{array}{l}158.45 \\
(0.302)\end{array}$ & $\begin{array}{l}147.76 \\
(0.398) \\
\end{array}$ \\
\hline AR(1) Test & $\begin{array}{l}-3.15 \\
(0.002)\end{array}$ & $\begin{array}{l}-3.09 \\
(0.002)\end{array}$ & $\begin{array}{l}-3.095 \\
(0.002)\end{array}$ \\
\hline AR(2) Test & $\begin{array}{l}-1.12 \\
(0.263)\end{array}$ & $\begin{array}{l}-1.08 \\
(0.283)\end{array}$ & $\begin{array}{l}-1.05 \\
(0.294)\end{array}$ \\
\hline Obs & 385 & 385 & 385 \\
\hline
\end{tabular}

TABLE III. ThE MOdEL BASICALLy ESTIMATES THE RESUlTS

Note: the variable parenthesis is standard error, Sargan test and AR test parenthesis are corresponding $\mathrm{P}$ values. “****, “***” and "**”mean significant at $1 \%, 5 \%$ and $10 \%$ levels, respectively.
The regression of model (1) results show that the goods in the issue of inventory has significant effects on the current inventory. Between the current inventory and inventory of the previous period have a positive correlations. House price and land supply have significant positive influence to inventory. So with the increase of house prices and land supply, inventory is also on the rise. Interest rates have a significant negative impact on inventory, with the increase of interest rate, the real estate enterprise financing costs, thereby reducing the supply of housing and inventory faster. Population density had no significant impact on the inventory. The model through the AR test and Sargan test shows that the selection of instrumental variables is reasonable and the model fitting effect is good. The regression of model (2) results show that after increasing prices squared, all variables impact on inventory were significantly. The coefficient of each variable symbol is consistent and have an order of magnitude with the model (1).House prices square coefficient is positive means that presents "U" shaped relationship between house prices and inventory, the price on the influence of the inventory may be nonlinear. The regression of Model (3) results show that after increasing the interaction item between housing price and per capita disposable income of urban residents, all variables have a significant impact on inventory, and the model not only has passed AR test and Sargan test but also has a good fitting effect. The regular interaction coefficient indicates that the increase of per capita disposable income can enhance the impact of housing price changes on inventory, and economic growth has a positive regulating effect on the relationship between housing price and inventory.

\section{2) Estimation of threshold effect of housing price on} inventory

According to the regression results of the above model, there is not only a non-linear relationship between housing price and inventory, but also the per capita disposable income of urban residents can amplify the impact of housing price changes on inventory. Therefore, the variable of per capita disposable income of urban residents will be taken as the threshold variable, and the threshold regression model will be adopted to specifically test the non-linear relationship between housing price and inventory. The econometric model is set as follows:

$$
\begin{gathered}
\operatorname{lnfsa_{it}=} \beta_{0}+\beta_{1} \ln p_{i t} I\left(p d c i_{i t} \leq \lambda_{1}\right)+\beta_{2} \ln p_{i t} I\left(\lambda_{1}<p c d i_{i t} \leq \lambda_{2}\right)+ \\
\beta_{3} \ln p_{i t} I\left(p c d i_{i t}>\lambda_{2}\right)+\beta_{4} C_{i t}+\varepsilon_{i t}(8)
\end{gathered}
$$


minimum residual sum of squares, and the "self-sampling" method was used to simulate the likelihood ratio test statistics, and the $\mathrm{P}$ value was compared with its critical value (Hansen, 1999). The search order of threshold values is first single threshold, then double threshold and triple threshold. "Table IV" shows the corresponding threshold effect test results:

TABLE IV. THRESHOLD REGRESSION RESULTS

\begin{tabular}{|l|l|l|l|l|l|}
\hline $\begin{array}{c}\text { Null hypothesis } \\
\left(\mathbf{H}_{\mathbf{0}}\right)\end{array}$ & \multicolumn{1}{|c|}{ F statistic } & \multicolumn{1}{|c|}{ P-value } & $\begin{array}{c}\text { The inspection } \\
\text { results }\end{array}$ & $\begin{array}{c}\text { The number of } \\
\text { Bootstrap }\end{array}$ & Threshold value \\
\hline No threshold & 52.19 & 0.0033 & Refuse & 300 & 10.0969 \\
\hline One threshold & 26.49 & 0.0100 & Refuse & 300 & 10.4072 \\
\hline Two thresholds & 8.45 & 0.5800 & accept & 300 & \\
\hline
\end{tabular}

"Table IV" shows that on the threshold regression of 35 large and medium cities nationwide, the F statistics obtained are respectively $52.19,26.49$ and 8.45 by the Bootstrap method (300). At the same time the P value is $0.0033,0.0100$ and 0.5800 respectively, which significantly declined "no threshold" and "there is a threshold method" but not rejected "there are two threshold values" assumption. Therefore, we can think that there are two threshold values, for the double threshold model. Specific threshold effect estimation results are shown in "Table V":

TABLE V. THRESHOLD EFFECT ESTIMATION RESUlTS

\begin{tabular}{|c|c|c|c|c|c|c|c|c|}
\hline Inls & Indp & Inlr & $\beta 1$ & $\beta 2$ & $\beta 3$ & R2(Within) & F Test & Number of samples \\
\hline $\begin{array}{l}0.630 * * * \\
(0.057)\end{array}$ & $\begin{array}{l}0.176 \\
(0.402)\end{array}$ & $\begin{array}{l}-0.625 * * * \\
(0.210)\end{array}$ & $\begin{array}{l}0.121(0.090 \\
)\end{array}$ & $\begin{array}{l}0.161 * \\
(0.085)\end{array}$ & $\begin{array}{l}0.215^{* * * *} \\
(0.083)\end{array}$ & 0.66 & 121.1 & 420 \\
\hline
\end{tabular}

Note: variable parenthesis is standard error, “***," “**”, and “"”mean significant at $1 \%, 5 \%$ and $10 \%$ levels, respectively.

As can be seen from "Table V", overall, the impact of housing price on inventory is positive, indicating that with the rise of housing price, inventory is increasing. By 35 large and medium cities of the country's threshold regression results can be seen that when the urban per capita disposable income is relatively low ( $\operatorname{lnp} d c i<10.0969$ ), the relationship between prices and inventory was not significant; but with the increase of urban per capita disposable income, housing prices rose to the level of inventories is increasing, it is consistent with the regression of the model (3) results. It shows that with the development of economy, the per capita disposable income of urban residents is gradually increasing, and the positive effect of inventory increase caused by the rising housing price is increasing. The reason for such a result may be that although the per capita disposable income of urban residents is increasing, the increase rate of per capita disposable income of urban residents is far lower than the rate of housing price rise, and the increase of income is not enough to form an effective demand for house purchase, so that the inventory increases rapidly. In fact, it is also consistent with the recent high real estate inventory in most cities across the country. In addition, between the land supply and inventory have significant positive correlation shows that with the increase of land supply, inventory increased significantly; while the negative relationship between interest rate and stock, as interest rates decline, the stock has risen, this may be for real estate enterprises, loan interest rates will decrease the cost of capital of real estate enterprises and increase of housing supply, so indirectly led to the increase of inventory; while the population density of inventory no significant effect.

\section{CONCLUSION}

By building a nonlinear dynamic panel measurement model and using data of 35 large and medium-sized cities from 2005 to 2016, this paper first verified the existence of non-linear relationship between housing price and inventory, and then conducted threshold regression on the modified model to verify the threshold effect between housing price and inventory. Results show that the double threshold effect between house prices and inventory, when the urban per capita disposable income is low, the positive relationship between house prices and the stock is not significant; but with the increase of urban per capita disposable income, housing prices for positive influence on strengthening inventory, illustrate urban per capita disposable income rose far lagged behind the house prices rise. It makes residents housing demand is insufficient and effectively making real estate inventory increase quickly.

At present, the real estate destocking control policy at the national level has come to an end. The following points should be paid attention to in the future precise control of the real estate market. First, lower house prices. In cities with large inventory, the government should focus on suppressing the sharp rise in housing prices, guiding housing prices to return to a reasonable range in the long run, increasing residents' income level, and effectively improving the imbalance between supply and demand in the housing market. Second, reducing financial leverage in the real estate market. At present our country is in a critical period of financial deleveraging, in order to reduce the financial risk of real estate market, not only to reduce financial institutions from the source to the various real estate development 
enterprise land capital credit support, strict controls of the real estate credit eventually flow, but also by raising the lending rates to reduce the real estate enterprise financing lever. Third, increasing land supply. With the implementation of government policies on a series of control housing prices in recent years, some recent first-tier cities inventory to effect is obvious, therefore, as for lower inventory city, the government should pay more attention to by increasing land supply to improve housing security, then foster and develop the housing rental market, so as to ensure the reasonable housing needs of low-income residents.

\section{REFERENCES}

[1] Chen Hong, Li Chao. Empirical study on factors affecting real estate inventory in China $[\mathrm{J}]$. Journal of $\mathrm{xi}$ 'an university of finance and economics, 2017, (4).

[2] Fang Yao. Analysis of influencing factors of real estate inventory in China [D]. Hefei: university of science and technology of China, 2016.

[3] Hansen B E. Threshold effects in non-dynamic panels: Estimation, testing, and inference [J]. Journal of Econometrics, 1999, (2).

[4] Hu Zuquan. Research on real estate destocking in China [J]. Macroeconomic management, 2016, (4).

[5] Li Xiaoman. Reasons for the simultaneous emergence of destocking and housing price boom in hot second-tier cities [J]. Finance \& economics, 2017, (11).

[6] Liu Bin, Sun Jiulun, Yao Yao. Promoting urbanization, reducing housing price and destocking of real estate [J]. Western BBS, 2017, (3).

[7] Liu Xing, Zhang Jing. Research on the relationship between money supply, real estate inventory and housing price $[\mathrm{J}]$. Financial regulation research, 2017, (6).

[8] Richard B, Stephen B. Initial Conditions and Moment Restrictions in Dynamic Panel Data Models [J].Journal of Econometrics, 1998, 87(1).

[9] Shen Bo. Impact of real estate industry on regional financial stability from the perspective of "destocking" - an empirical study based on spatial panel model [J]. Journal of Hebei university of economics and business, 2016, (3).

[10] Shen Xiaoqiang, Wu Sifang. Research on inventory of commercial housing in China and its digestibility [J]. China land science, 2015, (9).

[11] Struky R J. Understanding High Housing Vacancy Rate in a Developing Country [J].The Journal of Developing Areas, 1983.

[12] Wang Xianzhu, Wu Yidong. Research on regional differences of destocking pressure in China's housing market $[\mathrm{J}]$. Price theory and practice, 2016, (5).

[13] Wang Xiaoguang. Real estate inventory problem and countermeasures for destocking [J]. Theoretical exploration, 2017, (2).

[14] Wen Jianwu et al. Definition and statistical method of overseas housing vacancy rate [J]. China statistics, 2010, (12)

[15] Zhang Xiekui, Wu Siyi. Dynamic research on the impact of interest rate fluctuations on commercial housing inventory in China $[\mathrm{J}]$. Price theory and practice, 2016, (11).

[16] Zhou Youman. Analysis of China's real estate destocking situation and relevant countermeasures and Suggestions [J]. New finance, 2016, (9). 